Photoemission analysis of chemically modified $\mathrm{TIBr}$ surfaces for improved radiation detectors

A. J. Nelson, J. S. Lee, J. A. Stanford, W. K. Grant, L. F. Voss, P. R. Beck, R. T. Graff, E. L. Swanberg, A. M. Conway, R. J. Nikolic, S. A. Payne, H. Kim, L. Cirignano, K. Shah

August 9, 2013

SPIE Optics \& Photonics

San Diego, CA, United States

August 25, 2013 through August 29, 2013 
This document was prepared as an account of work sponsored by an agency of the United States government. Neither the United States government nor Lawrence Livermore National Security, LLC, nor any of their employees makes any warranty, expressed or implied, or assumes any legal liability or responsibility for the accuracy, completeness, or usefulness of any information, apparatus, product, or process disclosed, or represents that its use would not infringe privately owned rights. Reference herein to any specific commercial product, process, or service by trade name, trademark, manufacturer, or otherwise does not necessarily constitute or imply its endorsement, recommendation, or favoring by the United States government or Lawrence Livermore National Security, LLC. The views and opinions of authors expressed herein do not necessarily state or reflect those of the United States government or Lawrence Livermore National Security, LLC, and shall not be used for advertising or product endorsement purposes. 


\title{
Photoemission analysis of chemically modified TIBr surfaces for improved radiation detectors
}

\author{
A.J. Nelson ${ }^{* a}$, J.-S. Lee ${ }^{\mathrm{b}}$, J.A. Stanford ${ }^{\mathrm{a}}$, W.K. Grant ${ }^{\mathrm{a}}$, L.F. Voss ${ }^{\mathrm{a}}$, P.R. Beck ${ }^{\mathrm{a}}$, R.T. Graff ${ }^{\mathrm{a}}$, E.L. \\ Swanberg ${ }^{\mathrm{a}}$, A.M. Conway ${ }^{\mathrm{a}}$, R.J. Nikolic ${ }^{\mathrm{a}}$, S.A. Payne ${ }^{\mathrm{a}}$, H. Kim ${ }^{\mathrm{c}}$, L. Cirignano ${ }^{\mathrm{c}}$, and K. Shah ${ }^{\mathrm{c}}$ \\ ${ }^{a}$ Lawrence Livermore National Laboratory, Livermore, CA, USA \\ ${ }^{b}$ Stanford Synchrotron Radiation Lightsource, SLAC National Accelerator Laboratory, Menlo Park, \\ CA, USA \\ ${ }^{\mathrm{c} R a d i a t i o n}$ Monitoring Devices, Watertown, MA, USA
}

\begin{abstract}
Device-grade $\mathrm{TlBr}$ was subjected to various chemical treatments used in room temperature radiation detector fabrication to determine the resulting surface composition and electronic structure. Samples of as polished $\mathrm{TlBr}$ were treated separately with $2 \% \mathrm{Br}: \mathrm{MeOH}, 10 \% \mathrm{HF}, 10 \% \mathrm{HCl}$ and $96 \% \mathrm{SOCl}_{2}$ solutions. High-resolution photoemission measurements on the valence band electronic structure and $\mathrm{Tl} 4 \mathrm{f}, \mathrm{Br} 3 \mathrm{~d}, \mathrm{Cl} 2 \mathrm{p}$ and $\mathrm{S} 2 \mathrm{p}$ core lines were used to evaluate surface chemistry. Results suggest anion substitution at the surface with subsequent shallow heterojunction formation. Surface chemistry and valence band electronic structure were further correlated with the goal of optimizing the long-term stability and radiation response.
\end{abstract}

Keywords: Thallium bromide, photoelectron spectroscopy, radiation detection

\section{INTRODUCTION}

The development of room temperature radiation detectors requires new materials with large band gaps and high atomic number species. Thallium bromide (TlBr) meets these requirements having a wide band gap (2.68 eV), high $\mathrm{Z}$ $\left({ }^{81} \mathrm{Tl}\right)$ along with high resistivity $\left(10^{10}-10^{12} \Omega\right.$-cm). In addition, T1Br has long carrier lifetimes $\left(100 \mu \mathrm{s}, \mu \tau_{\mathrm{e}}>5 \times 10^{-3}\right.$ $\mathrm{cm}^{2} / \mathrm{V}$ ) and a demonstrated energy resolution of $1.2 \%$ at $662 \mathrm{keV} \cdot{ }^{1-4}$ However, $\mathrm{TlBr}$ detectors are susceptible to polarization phenomena that limit long term performance. ${ }^{5}$

Methods to control this polarization must address vacancy migration, surface chemistry and interfacial reactions at the contacts. Native oxides, surface stoichiometry and surface defects due to polishing all affect device performance. ${ }^{6}$ However, the long-term room temperature stability of $\mathrm{TlBr}$ gamma detectors has been improved using surface chemical modification but requires further investigation. ${ }^{7,8}$

This paper assesses and discusses the consequences and desirability of various chemical treatments of $\mathrm{TlBr}$. The surface chemistry and surface electronic structure were examined using UV and X-ray photoelectron spectroscopy (XPS). Understanding the surface electronic structure as a function of processing and using it to control the interfacial ionic conductivity has been elucidated with this experimental study.

\section{EXPERIMENTAL}

Device-grade $\mathrm{TlBr}$ samples were polished and separately immersed in $10 \% \mathrm{HCl}$ and $10 \% \mathrm{HF}$ solutions for 60 min. duration, $2 \% \mathrm{Br}: \mathrm{MeOH}$ for $60 \mathrm{sec}$. duration, all followed by a methanol rinse in air. A TlBr sample immersed in $96 \% \mathrm{SOCl}_{2}$ for $60 \mathrm{~min}$. duration was rinsed in DI water and blown dry with nitrogen. The chemically modified samples were subsequently transferred for analyses in a vacuum desiccator to preserve surface chemistry.

Quantitative compositional analysis of the resultant surface chemistry was performed immediately with XPS using a monochromatic Al Ka source $(1486.7 \mathrm{eV})$. The $200 \mu \mathrm{m}$ X-ray beam was incident normal to the sample and the 
detector is $45^{\circ}$ from normal. Core-level spectra were collected with pass energy of $23.5 \mathrm{eV}$, giving an energy resolution of $0.3 \mathrm{eV}$ that when combined with the $0.85 \mathrm{eV}$ full width half maximum (FWHM) Al Ka line width gives a resolvable XPS peak width of $1.2 \mathrm{eV}$. Deconvolution of non-resolved peaks was accomplished using Multipak 9.2 (PHI) curve fitting routines with Gaussian-Lorentzian line-shapes and a Shirley background. The collected data were referenced to an energy scale with binding energies for $\mathrm{Cu} 2 \mathrm{p}_{3 / 2}$ at $932.72+/-0.05 \mathrm{eV}$ and $\mathrm{Au} 4 \mathrm{f}_{7 / 2}$ at $84.01+/-0.05 \mathrm{eV}$. Binding energies were also referenced to the $\mathrm{C} 1 \mathrm{~s}$ photoelectron line arising from adventitious carbon at $284.6 \mathrm{eV}$.

The UV photoemission spectroscopy was performed at the Stanford Synchrotron Radiation Lightsource (SSRL), Menlo Park, CA. Monochromatic synchrotron radiation from the toroidal grating monochromator equipped beamline 8-1 was used to excite the $\mathrm{TlBr}$. Valence band (VB) photoemission spectra were obtained for each chemical treatment to observe the development of the electronic structure at the surface. The photoemitted electrons were analyzed using a spherical sector analyzer and were measured at normal emission with $\mathrm{h} v$ between 50 and $130 \mathrm{eV}$ and an energy resolution of $\Delta \mathrm{E} \approx 0.30 \mathrm{eV}$.

\section{RESULTS AND DISCUSSION}

Representative high magnification planar view secondary electron images (SEI) of the as-polished and $\mathrm{HCl}$ etched $\mathrm{TlBr}$ surfaces are presented in Figure 1. The observed morphology on the surface of the $\mathrm{HCl}$ etched $\mathrm{TlBr}$ is quite distinct from the rough as-polished surface.
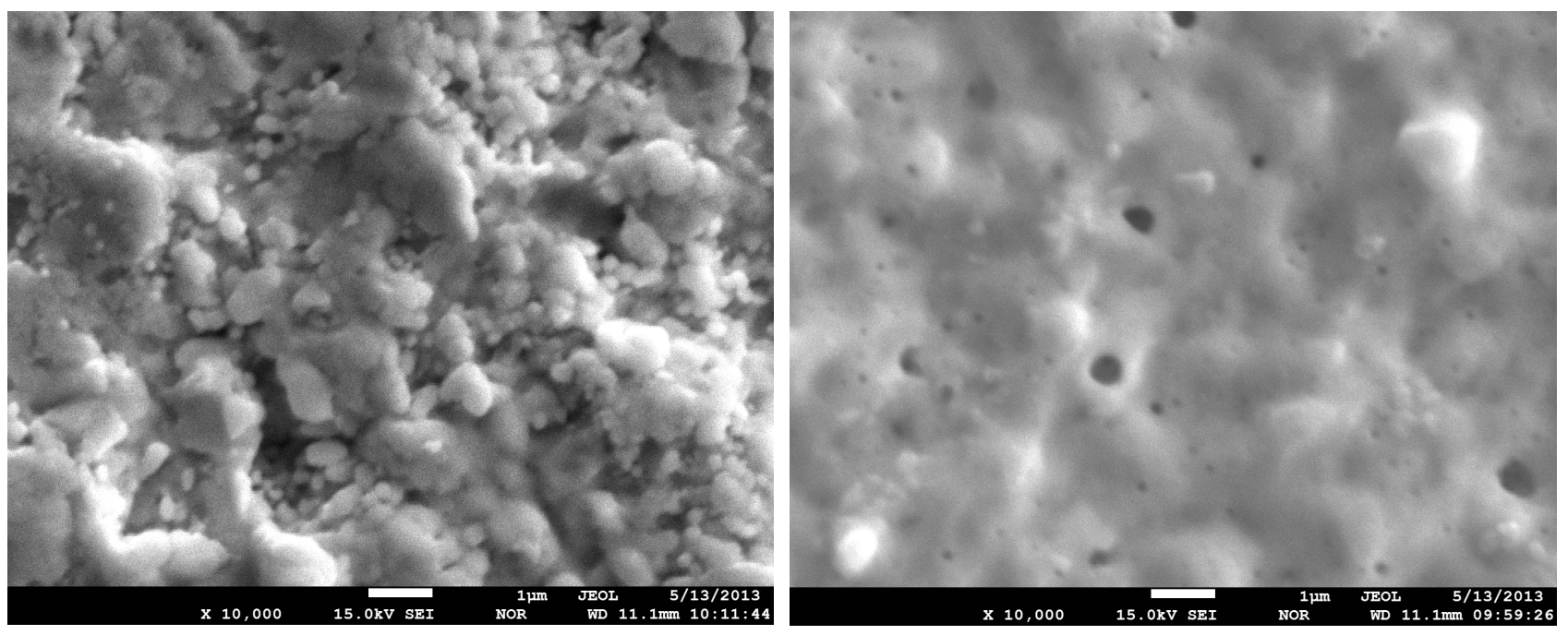

Figure 1. Plan view SEI of the (a) as-polished and (b) $\mathrm{HCl}$ etched $\mathrm{TlBr}$ surfaces

Quantitative XPS compositional analysis reveals that all of the etched surfaces have oxygen present and are Tlrich as summarized in Table I. The exception is the HF etched surface that is more stoichiometric but highly oxidized. The $\mathrm{HCl}$ and $\mathrm{SOCl}_{2}$ etched surfaces appear more Tl-rich than the polished surface unless the $\mathrm{S}$ and $\mathrm{Cl}$ are viewed as anions substituting for the $\mathrm{Br}$ in the near surface region. For the $\mathrm{HCl}$ etched surface, the $\mathrm{Tl} /(\mathrm{Br}+\mathrm{Cl})$ ratio is 1.15. Similarly for the $\mathrm{SOCl}_{2}$ etched surface, the $\mathrm{Tl} /(\mathrm{Br}+\mathrm{Cl}+\mathrm{S})$ ratio is 1.03 . These results suggest that indeed the anion species are substituting for the $\mathrm{Br}$ forming a different compound at the surface and thus possibly forming a shallow heterojunction given that the photoelectron escape depth is $1-3 \mathrm{~nm} .{ }^{10}$

Figure 2 presents the $\mathrm{Tl} 4 \mathrm{f}_{7 / 2,5 / 2}$ core-level spectra for the chemically modified series. From the literature, the $\mathrm{Tl}$ $4 \mathrm{f}_{7 / 2}$ binding energies for $\mathrm{Tl}$ metal, $\mathrm{Tl}_{2} \mathrm{O}\left(\mathrm{Tl}^{+1}\right), \mathrm{Tl}_{2} \mathrm{O}_{3}\left(\mathrm{Tl}^{+3}\right)$ and $\mathrm{TlBr}\left(\mathrm{Tl}^{+1}\right)$ are $117.1,119.1,118.6 \mathrm{eV}$ and $119.2 \mathrm{eV}$ respectively. ${ }^{11-15}$ In addition, the spin-orbit splitting for the $\mathrm{Tl} 4 \mathrm{f}$ peaks is $4.4 \mathrm{eV}$. Comparing these literature values with the $\mathrm{Tl} 4 \mathrm{f}_{7 / 2,5 / 2}$ binding energies summarized in Table II, we conclude that the surfaces have oxidized and that the $\mathrm{SOCl}_{2}$, $\mathrm{HCl}$ and $\mathrm{Br}: \mathrm{MeOH}$ treatments initially reduce the $\mathrm{Tl}$ surface oxide resulting in the small lower binding energy feature 
indicative of $\mathrm{Tl}$ metal. In addition, the chemical shift indicates supplementary bonding at the surface due to anion substitution resulting in a ternary compound and consequent heterojunction formation.

Table 1. Quantitative compositional analysis (atomic \%) of chemically modified $\mathrm{TlBr}$ surfaces.

\begin{tabular}{|c|c|c|c|c|c|c|c|}
\hline $\begin{array}{c}\mathrm{TlBr} \\
\text { treatment }\end{array}$ & $\mathrm{Tl}$ & $\mathrm{Br}$ & $\mathrm{O}$ & $\mathrm{Cl}$ & $\mathrm{S}$ & $\mathrm{F}$ & $\mathrm{Tl} / \mathrm{Br}$ \\
\hline $\begin{array}{c}\text { As- } \\
\text { polished }\end{array}$ & 36.84 & 33.59 & 29.57 & - & - & - & 1.10 \\
\hline $\mathrm{Br}: \mathrm{MeOH}$ & 35.85 & 27.80 & 36.35 & - & - & - & 1.29 \\
\hline $10 \% \mathrm{HF}$ & 12.60 & 13.60 & 73.72 & - & - & 0.08 & 0.93 \\
\hline $10 \% \mathrm{HCl}$ & 37.12 & 22.69 & 30.54 & 9.65 & - & - & 1.64 \\
\hline $\mathrm{SOCl}_{2}$ & 34.44 & 21.75 & 31.98 & 9.38 & 2.44 & - & 1.58 \\
\hline
\end{tabular}

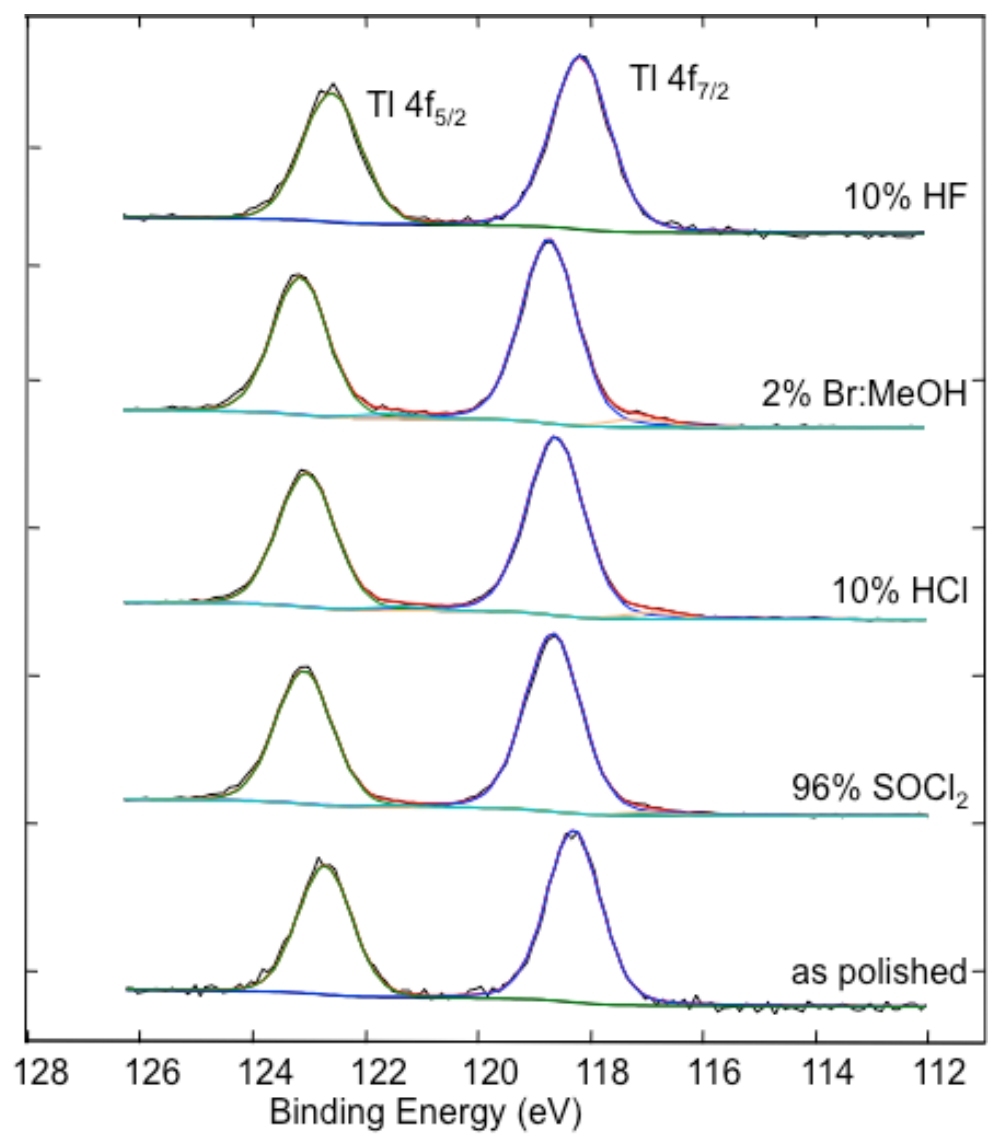

Figure 2. $\mathrm{Tl} 4 \mathrm{f}_{7 / 2,5 / 2}$ core-level spectra for the chemically modified $\mathrm{TlBr}$

The $\mathrm{Br} 3 \mathrm{~d}_{5 / 2,3 / 2}$ core-level spectra for the chemically modified $\mathrm{TlBr}$ series are presented in Figure 3 . The spinorbit pair peak separation is $1.0 \mathrm{eV}$ (Table II) and the binding energies are indicative of $\mathrm{Br}$ anion in $\mathrm{TlBr}$. ${ }^{9,16}$ Since there 
is no observed chemical shift in the $\mathrm{Br} 3 \mathrm{~d}$ peak, we conclude that these chemical treatments do not alter the chemical bonding of the $\mathrm{Br}$, but supports anion substitution and the formation of a ternary or quaternary compound at the surface, e.g. $\mathrm{TlBr}_{1-\mathrm{x}}\left(\mathrm{Cl}_{1-\mathrm{y}} \mathrm{S}_{\mathrm{y}}\right)_{\mathrm{x}}$.

Table $2 . \mathrm{Tl} 4 \mathrm{f}, \mathrm{Br} 3 \mathrm{~d}, \mathrm{~S} 2 \mathrm{p}$ and $\mathrm{Cl} 2 \mathrm{p}$ binding energies (eV) for chemically modified $\mathrm{TlBr}$ surfaces.

\begin{tabular}{|c|c|c|c|c|}
\hline $\mathrm{TlBr}$ treatment & $\mathrm{Tl} 4 \mathrm{f}_{7 / 2,5 / 2}$ & $\operatorname{Br} 3 d_{5 / 2,3 / 2}$ & $\mathrm{~S} 2 \mathrm{p}_{3 / 2,1 / 2}$ & $\mathrm{Cl} 2 \mathrm{p}_{3 / 2,1 / 2}$ \\
\hline As-polished & $118.3,122.7$ & $67.5,68.5$ & - & - \\
\hline $\mathrm{SOCl}_{2}$ & $\begin{array}{l}118.7,123.1 \\
117.1,121.5\end{array}$ & $67.9,68.9$ & $166.1,167.3$ & $197.4,199.0$ \\
\hline $10 \% \mathrm{HCl}$ & $\begin{array}{l}118.6,123.0 \\
116.9,121.4\end{array}$ & $67.8,68.8$ & - & $197.3,198.9$ \\
\hline $\mathrm{Br}: \mathrm{MeOH}$ & $\begin{array}{l}118.7,123.2 \\
117.2,121.6\end{array}$ & $67.9,68.9$ & - & - \\
\hline $10 \% \mathrm{HF}$ & $118.2,122.6$ & $67.6,68.6$ & - & - \\
\hline
\end{tabular}

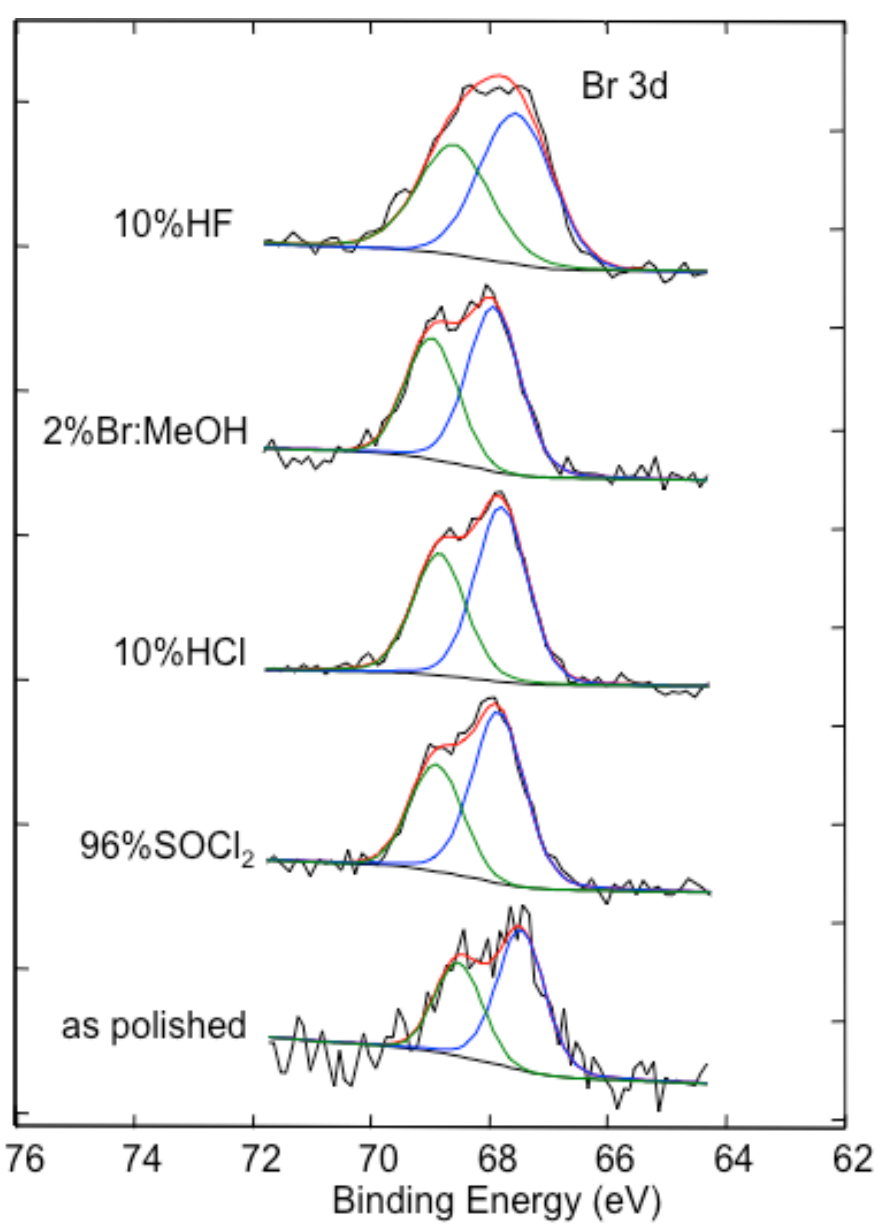

Figure 2 . $B r 3 d_{5 / 2,3 / 2}$ core-level spectra for the chemically modified $\mathrm{TlBr}$ 
Valence band spectra for each chemically treated $\mathrm{TlBr}$ surface acquired with $\mathrm{h} v=60 \mathrm{eV}$ are presented in Figure 3. The upper valence band (VB) is composed of $\mathrm{Tl} 6 \mathrm{~s}, 6 \mathrm{p}$ and $\mathrm{Br} 4 \mathrm{p}$ states and is where we expect to see the appearance of $\mathrm{Cl} 3 \mathrm{p}$ and $\mathrm{S} 3 \mathrm{p}$ states following chemical etching. ${ }^{21-25}$ Note that he upper $\mathrm{VB}$ of the as-polished $\mathrm{TlBr}$ standard shows features indicative of the $\mathrm{Br} 4 \mathrm{p}_{3 / 2,1 / 2}$ spin-orbit splitting with some $\mathrm{Tl} 6 \mathrm{~s}$ admixture evidenced by the non-standard $\mathrm{Br}$ $4 \mathrm{p}_{3 / 2,1 / 2}$ branching ratio. The small shoulder on the leading $\mathrm{VB}$ edge at $\sim 3.5 \mathrm{eV}$ is assigned to $\mathrm{Tl} 6 \mathrm{p}$ states.

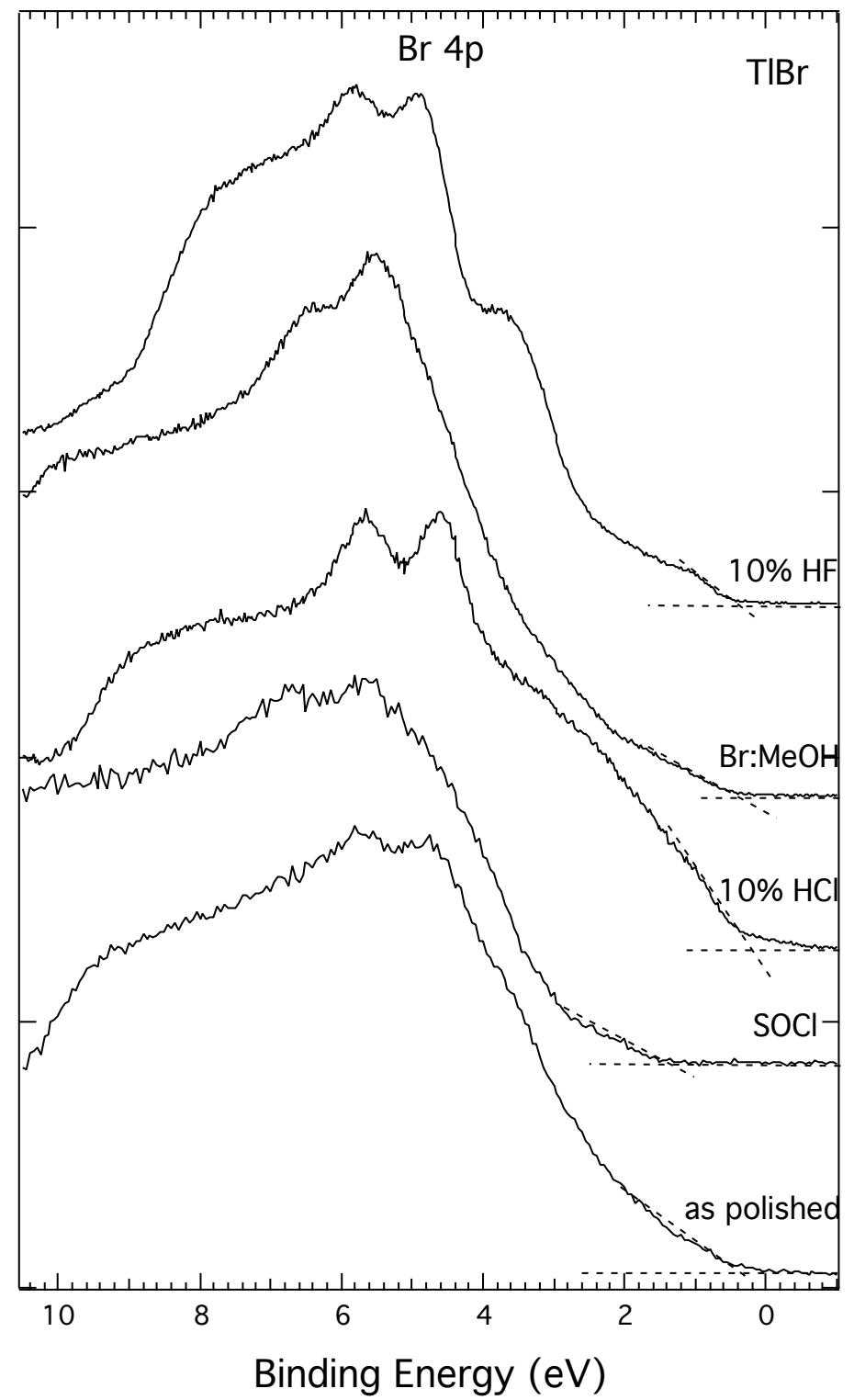

Figure 3. Valence band spectra for each chemically treated $\mathrm{TlBr}$ surface acquired with $\mathrm{h} v=60 \mathrm{eV}$

Upper valence band features are modified with each chemical treatment. Specifically, additional $\mathrm{Cl} 3 \mathrm{p}$ states admix with the $\mathrm{Tl}$ 6s states and the $\mathrm{S} 3 \mathrm{p}$ states admix with the $\mathrm{Tl} 6 \mathrm{p}$ states ${ }^{21}$ near the $\mathrm{VB}$ edge for the $\mathrm{SOCl}_{2}$ treated surface. At $\mathrm{h} v=60 \mathrm{eV}$, the $\mathrm{Cl} 3 \mathrm{p}$ photoionization cross-section is larger than that for both $\mathrm{Br} 4 \mathrm{p}$ and $\mathrm{S} 3 \mathrm{p} .{ }^{21}$ However, since the $\mathrm{Br}$ concentration at the surface is twice that of $\mathrm{Cl}$, the predominant features in the valence band are due to the $\mathrm{Br} 4 \mathrm{p}_{3 / 2,1 / 2}$ spin-orbit pair. ${ }^{16}$ Note that the modified surface electronic structure results in a $1 \mathrm{eV}$ shift of the valence band maxima (VBM) for $\mathrm{SOCl}_{2}$ treated $\mathrm{TlBr}$ as summarized in Table 3. 
Examining the upper valence band of the $\mathrm{HCl}$ treated surface, the $\mathrm{Br} 4 \mathrm{p}_{3 / 2,1 / 2}$ spin-orbit peaks are dominant but have an unusual branching ratio possible due to anion substitution with $\mathrm{Cl} 3 \mathrm{p}$ states. The admixed $\mathrm{Tl} 6 \mathrm{~s}$ state provides the broad background for both $\mathrm{Br} 4 \mathrm{p}$ and $\mathrm{Cl} 3 \mathrm{p}$ peaks. In addition, the sharp leading edge of the valence band is attributed to Tl $6 \mathrm{p}$ states. Note that the VBM for this chemically modified surface is $0.1 \mathrm{eV}$ lower relative to the as polished surface.

Table 3. Valence band maximum, $\mathrm{Tl} 5 \mathrm{~d}_{5 / 2,3 / 2}$ binding energies and ionization energy (eV) for chemically modified $\mathrm{TlBr}$ surfaces with $\mathrm{h} v=60 \mathrm{eV}$.

\begin{tabular}{|c|c|c|c|c|c|}
\hline TlBr treatment & VBM & $\mathrm{Tl}_{5} \mathrm{~d}_{5 / 2}$ & $\Delta \mathrm{E}_{\text {T15d5/2-VBM }}$ & $\begin{array}{c}\text { PE spectrum } \\
\text { width }\end{array}$ & $\mathrm{E}_{\text {ion }}$ \\
\hline \hline As-polished & 0.40 & 12.40 & 12.00 & 56.2 & 3.8 \\
\hline $\mathrm{SOCl}_{2}$ & 1.45 & 13.30 & 11.85 & 56.9 & 3.1 \\
\hline $10 \% \mathrm{HCl}$ & 0.30 & 12.25 & 11.95 & 56.4 & 3.6 \\
\hline $\mathrm{Br}: \mathrm{MeOH}$ & 0.47 & 13.00 & 12.53 & 57.0 & 3.0 \\
\hline $10 \% \mathrm{HF}$ & 0.45 & 12.35 & 11.90 & 56.2 & 3.8 \\
\hline
\end{tabular}

The branching ratio of the $\mathrm{Br} 4 \mathrm{p}_{3 / 2,1 / 2}$ spin-orbit peaks shown in Figure 3 for the $\mathrm{Br}: \mathrm{MeOH}$ treated surface is more typical since the compositional analysis revealed this surface to have a $\mathrm{Tl} / \mathrm{Br}$ of 1.29 (Table 1). The VBM for this $\mathrm{Br}: \mathrm{MeOH}$ modified surface is similar to the as polished surface with a comparable slope to the leading edge.

There are no F states with binding energies in the upper valence band for the HF treated TlBr. In addition, compositional analysis also showed minimal F present. Therefore, the structure at the VBM is attributed to strong Tl 6p emission from $\mathrm{Tl}^{0}$ followed by emission from $\mathrm{Tl}^{+1} 6 \mathrm{p}$ states. The $\mathrm{Br} 4 \mathrm{p}_{3 / 2,1 / 2}$ spin-orbit peaks are admixed with $\mathrm{Tl} 6 \mathrm{~s}$ states resulting in the observed branching ratio.

Table 3 also summarizes the width of the photoemission spectra acquired by measuring the secondary electron cutoff and the VBM with the sample biased. Subtracting the width of the entire photoemission spectrum for each treated $\mathrm{TlBr}$ surface from the exciting photon energy $(\mathrm{h} v=60 \mathrm{eV})$, the ionization energy $\mathrm{E}_{\mathrm{ion}}$ has been calculated. Unfortunately we were unable to calibrate the analyzer with clean $\mathrm{Au}$ foil during this experiment and thus unable to accurately determine the work function for each chemically modified surface. However, for reference, the work function $\phi_{\mathrm{s}}$ for $\mathrm{Tl}$ metal is $3.84 \mathrm{eV},{ }^{26}$ which is comparable to the calculated $\mathrm{E}_{\text {ion }}$ as summarized in Table 3 .

\section{CONCLUSIONS}

X-ray and UV photoelectron spectroscopy have been used to examine the surface chemistry and surface electronic structure of chemically modified T1Br. Plan view secondary electron images show that select chemical etching results in a smoother surface morphology. Photoemission results indicate that anion substitution at the surface forms a ternary compound that subsequently results in the formation a shallow $(1-3 \mathrm{~nm})$ heterojunction, especially for the $\mathrm{HCl}$ treatment. Improved device performance has been noted by increasing the concentration of the $\mathrm{HCl}$, which may indicate further conversion of the surface chemistry with consequent heterojunction formation.

\section{ACKNOWLEDGEMENTS}

This work performed under the auspices of the U.S. Department of Energy by Lawrence Livermore National Laboratory under Contract DE-AC52-07NA27344. The Domestic Nuclear Detection Office in the Department of Homeland Security also supported this work. Portions of this research were carried out at the 
Stanford Synchrotron Radiation Lightsource, a Directorate of SLAC National Accelerator Laboratory and an Office of Science User Facility operated for the U.S. Department of Energy Office of Science by Stanford University.

\section{REFERENCES}

[1] Hitomi, K., Onodera, T., Shoji, T., and He, Z. "Investigation of pixelated TlBr gamma-ray spectrometers with the depth-sensing technique”, Nucl. Instrum. and Meth. A 591, 276 (2008).

[2] Hitomi, K., Onodera, T., Shoji, T., Hiratate, Y. and He, Z. "TlBr Gamma-Ray Spectrometers Using the Depth Sensitive Single Polarity Charge Sensing Technique”, IEEE Trans. Nucl. Sci. 55, 1781 (2008).

[3] Churilov, A.V., Ciampi, G., Kim, H., Cirignano, L.J., Higgins, W.M., Olschner, F. and Shah, K.S., "Thallium Bromide Nuclear Radiation Detector Development”, IEEE Trans. Nucl. Sci. 56, 1875 (2009).

[4] Kim, H. Cirignano, L. Churilov, A.V. Ciampi, G., Higgins, W.M., Olschner, F. and Shah, K.S., "Developing Larger T1Br Detectors-Detector Performance", IEEE Trans. Nucl. Sci. 56, 819 (2009).

[5] Hitomi, K., Kikuchi, Y., Shoji, T., and Ishii, K., "Polarization Phenomena in TlBr Detectors", IEEE Trans. Nucl. Sci. 56, 1859 (2009).

[6] Oliveira, I. B., Costa, F. E., Kiyohara, P. K. and Hamada, M. M., "Influence of crystalline surface quality on $\mathrm{TlBr}$ radiation detector performance", IEEE. Trans. Nucl. Sci. 52, 2058 (2005).

[7] Conway, A. M., Voss, L. F., Nelson, A. J., Beck, P. R., Graff, R. T., Nikolic, R. J., Payne, S. A., Kim, H., Cirignano, L. J. and Shah, K., "Long-term room temperature stability of TlBr gamma detectors", Proc. SPIE 8142, 81420J (2011).

[8] Conway, A. M., Voss, L. F., Nelson, A. J., Beck, P. R., Laurence, T., Graff, R. T., Nikolic, R. J., Payne, S. A., Kim, H., Cirignano, L. J. and Shah, K., "Fabrication of Enhanced Stability of Room Temperature TlBr Gamma Detectors", IEEE Trans. Nucl. Sci. 60(2), 1231 (2013).

[9] Wagner, C.D., Riggs, W.M., Davis, L.E., Moulder, J.F. and Muilenberg G.E., [Handbook of X-ray Photoelectron Spectroscopy], Perkin-Elmer, Eden Prairie, (1979).

[10] Grant, J.T. and Briggs, D., [Surface Analysis by Auger and X-ray Photoelectron Spectroscopy] IM Publications, Chichester, (2003).

[11] McGuire. G.E., Schweitzer, G.K., Carlson, T.A., "Core electron binding energies in some Group IIIA, VB, and VIB compounds", Inorganic Chem. 12(10), 2450 (1973).

[12] Casella, I. G., Spera, R., "Electrochemical deposition of nickel and nickel-thallium composite oxides films from EDTA alkaline solutions", J. Electroanalytical Chemistry 578, 55 (2005).

[13] Vasquez, R.P., Siegal, M. P., Overmyer, D. L., Ren, Z. F., Lao, J. Y. and Wang, J. H., "Chemical bonding in T1 cuprates studied by x-ray photoemission", Phys. Rev. B 60(6), 4309 (1999).

[14] Lippens, P.E., Aldona, L., Olivier-Fourcadea, J., Jumasa, J.C., Gheorghiu de la Rocqueb, A., Senemaud, C., "Local electronic structure of T1-Sn-Te compounds", J. Phys. Chem. Solids 60, 1745 (1999).

[15] Glans, Per-Anders, Learmonth, T., Smith, K. E., Guo, J., Walsh, A., Watson, G. W., Terzi, F., Egdell, R. G., "Experimental and theoretical study of the electronic structure of $\mathrm{HgO}$ and $\mathrm{Tl}_{2} \mathrm{O}_{3}$ ", Phys. Rev. B71, 235109 (2005).

[16] Wagner, M. K., Hansen, J. C., deSouza-Machado, R., Liang, S., Tobin, J. G., Mason, M. G., Brandt, S., Tan, Y. T., Yang, A.-B., and Brown, F. C., "Surface morphology and growth of AgBr on Ag(111)", Phys. Rev. B43, 6405 (1991).

[17] Sakamoto, K., Eriksson, P. E. J., Mizuno, S., Ueno, N., Tochihara, H., and Uhrberg, R. I. G., "Core-level photoemission study of thallium adsorbed on a $\operatorname{Si}(111)-(7 \times 7)$ surface: Valence state of thallium and the charge state of surface Si atoms", Phys. Rev. B74, 075335 (2006).

[18] Kowalczyk, S.P., Kraut, E.A., Ewbank, M.D. and Harrison, W.A., "XPS Valence-Band Densities of States of Ternary Chalcogenide Crystals: Application to $\mathrm{Tl}_{3} \mathrm{AsSe}_{3}$ “, Jpn. J. Appl. Phys. Supplement 19-3, 377 (1980).

[19] Porte, L. and Tranquard, A., "X-ray photoelectron spectroscopy of thallium halide valence bands", Chem. Phys. Lett. 56, 466 (1978).

[20] Mizoguchi, H., Omata, T., Kawazoe, H., Fujitsu, S., Hosono, H. and Ueda, N., "Features of valence band structure of TlAlF 4 ", J. Phys.: Condens. Matter 8, 303 (1996).

[21] Yeh, J.J. and Lindau, I., "Atomic Subshell photoionization cross sections and assymetric parameters: $1 \leq Z \leq 103$ ", Atomic Data Nucl. Data Tables 32, 1 (1985).

[22] Shimosaka, W., and Kashida, S., "Electronic Structure of Tetragonal and Monoclinic TlS Crystals", J. Phys. Soc. Jpn. 73(6), 1532 (2004).

[23] Zheng, Jin-Cheng, Huan, C. H. A., Wee, A. T. S., and Kuok, M. H., "Electronic properties of $\mathrm{CsSnBr}_{3}$ : studies by experiment and theory", Surf. Interface Anal. 28, 81 (1999). 
[24] Ohnishi, A., "Optical Spectra of Inorganic-Organic Compounds $\left(\mathrm{C}_{2} \mathrm{H}_{5} \mathrm{NH}_{3}\right)_{2} \mathrm{CdCl}_{4}$ in 3-30 eV Range", J. Phys. Soc. Jpn. 70(11), 3424 (2001).

[25] Lin, S.F. and Spicer, W.E., "Ultraviolet-photoemission studies of T1Cl", Phys. Rev. B 14, 4559 (1976).

[26] Michaelson, H.B., "The work function of the elements and its periodicity", J. Appl. Phys. 48, 4729 (1977). 